\title{
Pharmacists' knowledge and attitudes about natural health products: a mixed-methods study
}

\author{
This article was published in the following Dove Press journal: \\ Drug, Healthcare and Patient Safety \\ 30 January 2014 \\ Number of times this article has been viewed
}

\author{
Nadir Kheir \\ Hoda Y Gad \\ Safae E Abu-Yousef \\ College of Pharmacy, Qatar University, \\ Al Tarfa, Doha, Qatar
}

Objectives: To explore knowledge and attitude of pharmacists in Qatar towards natural health products (NHPs).

Methods: The quantitative component of this study consisted of an anonymous, online, selfadministered questionnaire to assess knowledge about NHPs among pharmacists in Qatar. Descriptive statistics and inferential analysis were conducted using Statistical Package of Social Sciences $\left(\right.$ SPSS $\left.^{\circledR}\right)$. Means and standard deviation were used to analyze descriptive data, and statistical significance was expressed as $P$-value, where $P \leq 0.05$ was considered statistically significant. Associations between variables were measured using Pearson correlation. The qualitative component utilized focus group (FG) meetings with a purposive sample of community pharmacists. Meetings were conducted until a point of saturation was reached. FG discussions were audio-taped and transcribed verbatim. Data were analyzed using a framework approach to sort the data according to emerging themes.

Results: The majority of participants had average to poor knowledge about NHPs while only around 7\% had good knowledge. In the FG meetings, participants considered the media, medical representatives, and old systems of natural health as major source of their knowledge. They criticized undergraduate pharmacy courses (for inadequately preparing pharmacists to deal with NHPs) and the pharmacy regulations (for being irrelevant). A perception of NHPs as being "safe" still exists among pharmacists.

Conclusions: Pharmacists' ability to provide effective services associated with NHPs is limited by poor access to evidence-based information and poor knowledge. A perception of NHPs and CAM as 'safe' still exists among pharmacists, and regulations related to NHPs require addressing to follow best practice and ensure patient safety.

Keywords: Qatar, focus group, complimentary alternative medicine

\section{Introduction}

The use of herbal and other natural health products (NHPs) in the treatment of disease has increased significantly due to patient dissatisfaction with current conventional medicines and the costs associated with them. ${ }^{1-3}$ This widespread use of NHPs has meant that health care professionals, and pharmacists in particular, need to become knowledgeable about this modality of treatment and its place in therapy. ${ }^{2-7}$ In a study that utilized interviews with pharmacists and stakeholders, including leaders representing consumers, complementary and alternative medicine (CAM) practitioners and conventional health care practitioners, participants described the pharmacists' professional role associated with NHPs to be similar to their expected role when dispensing overthe-counter medicines. ${ }^{4}$ Stakeholder leaders in this study did not expect pharmacists
Correspondence: Nadir Kheir

College of Pharmacy, Qatar University,

Al Tarfa, Doha 27I3, Qatar

Email nadirk@qu.edu.qa 
to be experts, but expected them to have a basic level of knowledge about NHPs. However, the National Association of Pharmacy Regulatory Authorities' Model Standards in Canada require that pharmacists ask about NHP use when counseling patients, and when asked they should provide accurate information regarding the efficacy, toxicity, side effects, or interactions of NHPs. ${ }^{5,6}$

Faced with the increasing demand for CAM and NHPs by their patients, pharmacists have to be prepared to discuss their uses and limitations, as well as any possible adverse effects. They should be able to watch for signs of noncompliance with prescribed conventional treatments that may be associated with the use of these products, as this is often not explicitly reported by patients. ${ }^{2,4}$ Although some studies show that a significant number of people use NHPs as an alternative to conventional medicines, many studies indicated that most people use NHPs as a complement to conventional medicines. ${ }^{2-7}$ This means that many patients may be at risk of potential drug-related problems (DRPs) (eg, drug-herb interactions, medication nonadherence) associated with the concomitant use of NHPs and other medications. ${ }^{7}$ Furthermore, most NHP users do not voluntarily reveal their usage of these products to their physicians without prompting, but are more likely to reveal this to pharmacists. ${ }^{8}$ These findings suggest high potential for preventable DRPs and suboptimal medication use, particularly among people who suffer from chronic illness. As such, this represents a tremendous opportunity for pharmacists to identify, resolve, or prevent actual and potential DRPs among their patients and to promote the safe and appropriate use of medications. However, it has been reported that many pharmacists feel insufficiently informed about CAM and in particular herbal medicines. ${ }^{9}$ While consumer interest in NHPs has continued to rise, schools of pharmacy, nursing, and medicine have been slow to introduce curriculum changes aimed at preparing practitioners with the required skills and knowledge related to NHPs. A number of factors contributing to the passive attitude on the part of academicians and practitioners alike toward developing relevant topics and teaching strategies related to NHPs in pharmacy schools or in practice have been reported. ${ }^{10}$ Many cite "lack of scientific evidence" as a concern, while others simply admit that they were unfamiliar with many of the CAM products and services that their patients are using. Despite these concerns, many students and faculty groups expressed positive attitudes toward the use of NHPs (and CAM) and advocated their use in certain situations. ${ }^{11,12}$ To close the circle, an awareness of the attitudes and beliefs of health care professionals, who may influence a patient's self-care decision about these alternative modalities of treatments, seems to be warranted.

To date, no studies have been published to report pharmacists' knowledge of NHPs or to explore their attitudes toward these products in Qatar. Therefore, the main objectives of this project were: 1) to assess pharmacists' level of scientific knowledge related to NHPs; 2) to explore the attitude of pharmacists toward NHPs and CAM in general; 3) to gauge pharmacists' opinion about the reference sources related to NHPs available to them; 4) to understand the state of regulatory aspects related to NHPs; and 5) to identify the challenges and barriers facing pharmacists when dealing with NHPs.

\section{Materials and methods}

This was an exploratory and descriptive study utilizing a mixed qualitative-quantitative method conducted from October to December 2011 in Qatar. The study was approved by Qatar University's Institutional Review Board (approval number QU-IRB 89/11).

\section{Quantitative study}

To assess pharmacists' scientific knowledge, a questionnaire was developed utilizing information available in the literature and discussions with experts in the field of NHPs. ${ }^{7,13,14}$ To maximize relevance, the questions were developed by a senior faculty member with extensive experience of planning, development, and delivery of the pharmacy courses that deliver the bulk of the knowledge that relates to NHPs. The questions were developed such that they were within the expected level of a pharmacy college graduate, and all (except one) addressed specific herbal products widely available in community pharmacies and commonly used by patients. The acceptability, burden, and comprehension of the questionnaire were assessed by gauging expert opinion of two faculty members with expertise in questionnaire development, then piloting on seven pharmacists, none of whom participated in the study. Feedback of the two groups was discussed by the research team, and proposed changes were considered for inclusion in the questionnaire. The final questionnaire included eight items addressing demographics (sex, age, highest pharmacy degree obtained, past country of practice, years of experience as pharmacist, years since graduation, country where pharmacy degree was obtained, NHP-related courses completed [if any]) and a knowledge section (twelve items) (Figure 1). Six items in the knowledge section were multiple choice questions, each with a single correct answer. The other six questions were true/false questions. The total score for the knowledge section was arbitrarily divided into 
poor knowledge (0-3), average knowledge (4-8), and good knowledge (9-12). A final global question asked pharmacists subjectively to assess their level of confidence in their knowledge of NHPs. The questionnaire was disseminated through an online database (SurveyMonkey, Palo Alto, CA, USA) to pharmacists practicing in Qatar whose contact addresses were available at the College of Pharmacy's database. Means and standard deviations were used to analyze descriptive data (parametric method), and statistical significance was expressed as $P$-value, where $P \leq 0.05$ was considered statistically significant. Associations between variables were measured using Pearson correlation, and data were analyzed using the SPSS version 19 (IBM Corporation, Armonk, NY, USA).

\section{Qualitative study}

To explore attitudes toward NHPs, focus-group (FG) discussions were conducted, with pharmacists recruited using mixed purposive and "snowball" sampling techniques. ${ }^{15}$ Pharmacists were invited to take part in the FG meetings if they were working in a community pharmacy in Qatar for no less than 1 year and were known by the researchers to be able to provide diverse and deep perspectives on the subject matter. Pharmacists were also asked to recommend others who they perceived to have insight and experience with NHPs who could enrich the discussions. All candidates were then emailed a letter of invitation describing the study and their expected role. Those who agreed to participate provided consent before being interviewed. The FG meetings took place during October and November 2011 in a primary health care clinic's meeting room after regular business hours. Each of the interviews took approximately 1.5-2 hours. Questions for the FG meetings were grouped under the following main areas: perception about NHPs and CAM, sources of NHP knowledge, NHP regulations, and challenges and barriers when dealing with NHPs. Interviews were conducted following a systematic approach (opening, introductory, transitional, key, and closing questions). At the beginning of each interview, the aim of the study was shared with the pharmacists. Discussions during FGs were audiotaped and transcribed verbatim, and all interviews were conducted by the same two interviewers. After reaching a point of saturation, no additional interviews were conducted. Data were analyzed using a framework approach (familiarization, generating codes, identifying themes) to sort the data according to emerging themes. ${ }^{16,17}$

\section{Results}

A total of 92 pharmacists (55\% females) responded to the quantitative questionnaire ( $25 \%$ response rate). Over $60 \%$
Table I Demographic characteristics of the pharmacists $(n=92)$

\begin{tabular}{|c|c|c|}
\hline & Number & Frequency \\
\hline \multicolumn{3}{|l|}{ Sex } \\
\hline Female & 51 & $55.4 \%$ \\
\hline Male & 41 & $44.6 \%$ \\
\hline \multicolumn{3}{|l|}{ Age (years) } \\
\hline $20-29$ & 19 & $20.7 \%$ \\
\hline $30-39$ & 51 & $55.4 \%$ \\
\hline $40-49$ & 16 & $17.4 \%$ \\
\hline$>50$ & 06 & $6.5 \%$ \\
\hline \multicolumn{3}{|l|}{ Highest level of education } \\
\hline Bachelor's & 74 & $80.4 \%$ \\
\hline Master's & 7 & $8.6 \%$ \\
\hline PharmD & 3 & $3.2 \%$ \\
\hline $\mathrm{PhD}$ & 3 & $3.2 \%$ \\
\hline Others & 5 & $5.4 \%$ \\
\hline \multicolumn{3}{|l|}{ Pharmacy practice setting } \\
\hline Community pharmacies & 17 & $20.0 \%$ \\
\hline Public hospital pharmacies & 44 & $51.8 \%$ \\
\hline Private hospital pharmacies & 02 & $2.40 \%$ \\
\hline Primary health care pharmacies & 16 & $18.8 \%$ \\
\hline Others & 06 & $7.1 \%$ \\
\hline \multicolumn{3}{|l|}{ Years' practice in Qatar } \\
\hline$<5$ & 19 & $21.0 \%$ \\
\hline $6-10$ & 25 & $27.5 \%$ \\
\hline $11-15$ & 30 & $33.0 \%$ \\
\hline$>15$ & 17 & $18.7 \%$ \\
\hline \multicolumn{3}{|l|}{ Completed CAM courses } \\
\hline Yes & 10 & $11.1 \%$ \\
\hline No & 80 & $88.9 \%$ \\
\hline
\end{tabular}

Abbreviation: CAM, complementary and alternative medicine.

of the respondents practiced in the hospital and primary health care setting, and only $20 \%$ in community pharmacies (Table 1). The highest pharmacy degree of the majority of pharmacists was a bachelor's.

\section{NHP knowledge}

Half of all the participants had average knowledge about NHPs, with a mean score of $4.51( \pm 3.57)$, and over $30 \%$ of the sample had poor knowledge (Table 2). The results showed that female pharmacists had higher knowledge scores than males $(P<0.05)$, and pharmacists in community pharmacies possessed more knowledge than pharmacists practicing in other settings $(P<0.05)$. Also, knowledge tended to increase as pharmacists years of practice increased. Around 35\% of respondents indicated that they were somewhat confident or not confident in their NHP-related knowledge, whereas only $7.6 \%$ rated themselves as confident. However, $28 \%$ of the sample did not respond to this question.

In the qualitative arm of the study, four FG meetings were conducted with a total of 18 pharmacists (or "participants", a term that we will use interchangeably with "pharmacists") before reaching theoretical 


\section{Please choose the single best answer for every question}

1. From the list, please select all that apply to complementary and alternative medicine (CAM)
a) Herbal products
b) Vitamin supplements
c) Massage
d) Acupuncture
e) Homeopathy
f) Traditional Chinese medicine

2. Which one of the following herbal products should not be taken by patients who are taking digoxin?
a) Echinacea
b) Saw palmetto
c) St John's wort
d) Valerian

3. Fatima has been using cranberry to treat her urinary tract infection. Her symptoms have not improved since she started taking cranberry capsules (four $400 \mathrm{mg}$ capsules daily) 2 days ago. What is the most likely reason for cranberry ineffectiveness in this case?

a) She is not taking a high enough
dose of cranberry to be effective.

b) Only unsweetened cranberry juice, not capsules, has been shown to work in clinical trials.

c) It takes more than 48 hours to see the full effects of cranberry extract.

d) It is not clear that cranberry will work to treat urinary tract infections.

4. Which of the following is most correct regarding the efficacy of black cohosh for the management of menopausal symptoms?
a) Black cohosh appears to be as effective as hormone-replacement therapy for the management of symptoms associated with menopause.
b) Black cohosh may help relieve hot flashes associated with menopause only.
c) Black cohosh has been shown to relieve hot flashes and provide protection against developing osteoporosis.
d) Black cohosh has been shown to relieve hot flashes and provide protection against cardiac disease.

5. Which of the following can be used to treat motion sickness in pregnant women instead of diphenhydramine?
a) Echinacea
b) Ginseng
c) Saw palmetto
d) Ginger

6. What herb is routinely used to improve the symptoms of an enlarged prostate?
a) Ginkgo biloba
b) Garlic
c) Saw palmetto
d) Echinacea

\section{True/false questions}

1. Garlic can lower blood lipid level
a) True
b) False
c) Don't know

2. Echinacea is commonly used for cold and flu symptoms
a) True
b) False
c) Don't know

3. Ginseng can be used safely in people with high blood pressure
a) True
b) False
c) Don't know

4. Valerian should be used cautiously in patients using benzodiazepines
a) True
b) False
c) Don't know

5. Ginkgo is claimed to delay dementia.
a) True
b) False
c) Don't know

6. Garlic may make birth-control pills more effective
a) True
b) False
c) Don't know

Figure I Natural health product knowledge questions.

saturation. Table 2 illustrates the questions and the emerging themes identified throughout the FG meetings. Participants listed a variety of NHPs that they dispense or sell from their pharmacies, including ivy leaf extracts, dietary supplements, vitamins, products to relief hemorrhoid symptoms, energy boosters (such as ginseng), immune system enhancers (such as echinacea), valerian, St John's wort, glucosamine, and Ginkgo biloba.

\section{Perception of CAM}

Interviews were started by gauging the pharmacists' perception about the general area of CAM and specifically what 
Table 2 Questions and themes identified in focus-group meetings

\begin{tabular}{ll}
\hline Question & Theme \\
\hline $\begin{array}{l}\text { Perception about } \\
\text { CAM and NHPs }\end{array}$ & $\begin{array}{l}\text { Pure and safe, confusing to patients and } \\
\text { pharmacists } \\
\text { Ayurveda (traditional herbal system of } \\
\text { kource of NHP }\end{array}$ \\
$\begin{array}{l}\text { healing), the Internet, medical representatives, } \\
\text { no access to reliable sources }\end{array}$ \\
$\begin{array}{l}\text { Barriers and challenges } \\
\text { when dealing with }\end{array}$ & $\begin{array}{l}\text { to evidence-based knowledge, language } \\
\text { and cultural barriers, ethical issues (profit- }\end{array}$ \\
CAM and NHPs & $\begin{array}{l}\text { generating versus professionalism) } \\
\text { Old, irrelevant, incomplete }\end{array}$
\end{tabular}

Abbreviations: CAM, complementary and alternative medicine; NHPs, natural health products.

NHPs meant to them. Two contradictory themes emerged; the first was that these products were confusing to the patient and the pharmacist. One pharmacist (FG1\#1: in the first FG conducted, coded number 1) noted that, "What comes to my mind is lots of products from many companies that make the patient dizzy finding the best product; fear also comes to my mind when someone asks because I don't have enough knowledge." Another pharmacist (FG2\#1) mentioned that, "Herbal medicines are mixtures of herbs and we can't predict; that's what made me confused."

The second theme was that NHPs are parts of a system that has been established as a safe modality of healing and that is rooted in old traditions of healing. FG4\#3 stated, "Can't tell it's dangerous, no studies, so mostly it's safe." Several pharmacists referred to Ayurveda (an ancient system of healing that revolves around herbal products, originating from the Indian subcontinent) and described it as a reliable healing system encompassing all NHPs. Other pharmacists described NHPs as part of a system not only of herbal products, but one that includes "acupuncture, reflexology, and surgery."

Some of the participants cautioned about the indiscriminate use of NHPs. FG1\#3 commented, "Every product should be handled with care, and as long as it is handled with care, it's not at all dangerous." Another pharmacist (FG4\#2) was more cautious about their use: "For me, the use of NHPs is a threat because people don't look at the quantity used, and they think that if they take more, it will give a better effect."

Other perceptions about CAM and NHPs noted from the four FGs were that NHPs are "just lots of colored and fancy bottles" or "totally safe and approved by the public." Others thought that CAM and NHPs are anything that is not pharmacological. One pharmacist (FG1\#1) emphasized that natural remedies represented to him "a pure thing with $100 \%$ benefit to the public health."

\section{Reference sources}

FG participants considered undergraduate courses, medical representatives, and the Internet as major reference sources related to NHPs. But the unavailability of reliable scientific sources for NHP information was a strong theme throughout the four FGs. One of the pharmacists (FG3\#4) mentioned that the main source of their NHP knowledge was various TV programs: "We didn't learn from a college, I learned from programs such as Opera and Doctors, then people start to know and call to ask about them." Another emerging theme was the role of ancient systems of traditional medicine such as Ayurveda as source of knowledge (this was a theme that emerged clearly from among pharmacists whose origin was the Indian subcontinent). These natural remedies were again described as "safe." One of the FG pharmacists (FG2\#1) noted that, "We hear about the medicinal plants from our parents; like even for minor conditions like sneezing or fever, we used to take some herbs from our parents. This was our childhood habit." Another participant (FG1\#4) emphasized, "We don't have any resources for updating knowledge."

The majority of the participants reported that they tend to update their knowledge when receiving new products or when patients ask about certain products. One of the participants (FG1\#2) stressed the importance of self-initiated effort to upgrade one's knowledge, suggesting, "Regarding the resources, that depends upon the person, you know, if you are more interested, if you want to refresh or increase your knowledge that depends on you." The same pharmacist went on to admit, "We don't have any resources for updating knowledge."

\section{Challenges and barriers}

There was almost a consensus that what had been taught in undergraduate pharmacy courses was insufficient to prepare the pharmacist for practice and presented a barrier in their daily dealings with NHPs. FG4\#3 said, "Colleges didn't prepare pharmacists enough in how to seek information." Another pharmacist (FG2\#4) explained that, "It was more science-based teaching, focused more on the plant itself; it wasn't sufficient to prepare pharmacists for practice." The undergraduate courses that were received and that were designed to address NHPs were described as irrelevant. FG3\#5 noted, "From undergraduate courses, we had only one course called pharmacognosy, which provided only the basics about natural health products and wasn't sufficient to prepare pharmacists for practice."

Ethical dilemmas were another recurring theme, where some of the participants expressed concern that the large 
profit margin (and sometimes the financial bonus) associated with the sale of these products in large quantities presents a sense of pressure on them. FG2\#5 said, "Business forces you to do things you don't agree with, and there is a bonus for the sales," and FG2\#2 added, "I sell it and I know they are not that effective compared to pharmacological drugs."

\section{NHP regulations}

Two themes were noted in relation to regulations. The first was the lack of detailed, complete, and clear regulations that govern the sale of NHPs, which was a barrier when dispensing or counseling about these products and services. Several pharmacists criticized the current regulations related to NHPs and CAM describing them as old, undefined, and "permissive." However, one pharmacist disagreed: "Regulations in Qatar are enough, because these products are generally easily handled, such as vitamins or amino acids, so fewer registrations and regulations are required." Other emerging themes were the need for regulations that define the pharmacist's role in dispensing NHPs, and a perception that regulations in Western countries were more adequate in comparison to Qatar and other neighboring Gulf countries.

\section{Discussion}

The findings of this research project touch on issues of patient safety, professional practice, pharmacists' educational and training needs, and regulatory issues. Our cohort of pharmacists scored poorly in the knowledge questions, and this correlated strongly with the pharmacists' self-assessment of their confidence in their knowledge of NHPs. Interestingly, but probably not unexpectedly, poor knowledge related to NHPs is not unique to this group of pharmacists or to Qatar. ${ }^{1-4}$ Arguably, poor knowledge reflects on the degree of confidence the pharmacist possesses while dispensing or recommending these products, and more importantly, on the quality and validity of the information provided in these circumstances.

We chose to investigate pharmacists' attitudes and opinions about a set of areas related to NHPs through a qualitative approach rather than a structured and rigid quantitative approach, because of the well-established ability of the qualitative technique in exploring the complexities of a phenomenon and its value in creating an in-depth understanding of the participant's experience. ${ }^{18}$ In the qualitative arm of the study, the data generated suggested that pharmacists' ability to counsel patients on NHPs is limited by poor access to evidence-based information. The challenges associated with access to information resources coupled with poor knowledge, too, had been reported in the international literature, making it an international phenomenon. ${ }^{19}$ Pharmacists in our study criticized undergraduate courses that were designed to provide information related to NHPs, and described them as "irrelevant." Work conducted elsewhere suggested that undergraduate pharmacy courses fell short of addressing real needs of practicing pharmacists to provide adequate NHP-related counseling. ${ }^{20}$ The findings of the current study and of other studies conducted elsewhere in respect to the status of pharmacists' knowledge and to the perception of pharmacists on undergraduate pharmacy courses clearly reveal a problem of global prevalence, and call for reassessment and reengineering of undergraduate pharmacy courses with the aim of designing and delivering topics relevant to NHPs. It is probably not only the course content that requires reassessment and modifying, but also the method of delivery and how these courses are integrated within the overall pharmacy curriculum utilizing a course-integrated strategy. Our findings mirror what had been reported elsewhere, which suggests that while the sale of NHPs and dietary supplements in pharmacies is high, pharmacists are ill equipped to counsel patients about these products. ${ }^{21}$ This situation has led some to question the ethics of pharmacists selling NHPs and dietary supplements and to highlight the existence of an ethical conflict stemming from the profit motive associated with sales of NHPs and dietary supplements. ${ }^{21}$ Indeed, our FG pharmacists expressed these conflicts and described them as stress factors that present challenges and barriers in their day-to-day work with NHPs. These views were nevertheless alarming, as they illustrate ethical dilemmas in which pharmacists sometimes resort to making decisions influenced by the desire toward making financial gains rather than to their client's well-being or health-related needs. The financial gains do not necessarily directly go to them, but to the business owner. The indirect benefit they get, however, is an increased business profit that helps them hold onto their job at the respective pharmacy.

Pharmacy regulations were a point of concern among FG pharmacists. There seems to be a lack of current and clear regulations governing the sale of NHPs and services. In comparison with Western countries, pharmacists thought that the available NHP-related regulations in Qatar fell short of ensuring best practice in sale and counseling patients seeking these products. This is probably a fair assumption. In Canada, for example, explicit policies or guidelines regarding pharmacists' professional responsibilities with respect to NHPs currently exist in the majority of jurisdictions..$^{9,10}$ 
Some pharmacists perceived CAM products made from herbal or plant origins as "safe," with several pharmacists who grew up or were educated in the Indian subcontinent speaking highly about an ancient system that is considered a reliable source of information about herbal products (ie, Ayurveda). These pharmacists were more likely to describe CAM and NHPs as pure and safe. Claims of safety of NHPs, in particular Ayurveda, should be considered with caution and have been challenged. A study from the US raised concerns about Ayurveda, pointing out that $20 \%$ of US and Indian-manufactured Ayurveda patent medicines sold via the Internet contained toxic levels of heavy metals, such as lead, mercury, and arsenic. ${ }^{22}$ Other concerns include the absence of published studies, a lack of consistent manufacturing processes and quality standards, and a fear of adulteration. ${ }^{23}$

Finally, and as expected, the response rate was poor, and this is probably because only those pharmacists who deal with NHPs would respond to the survey. We cannot with any degree of certainty provide an accurate figure of those pharmacists who responded to this questionnaire as a percentage from the actual target population (ie, pharmacists who stock and dispense NHPs from their pharmacies). We must also point out that we only had access to Qatar-based pharmacists with contact addresses with the College of Pharmacy at the time of the survey, and this limits the generalizability of the results.

In the qualitative arm of the study, the reason for conducting only five FG meetings was that ideas generated from the meetings started to recur, and that signaled theoretical saturation point. It should be noted that qualitative methodology (including FG meetings) does not require large sample sizes nor does it focus on generalizability of results. ${ }^{17}$ These are exploratory strategies, and considering the information retrieved, we believe we accomplished the objective of conducting the FG meetings.

\section{Conclusion}

Pharmacists' ability to provide effective services associated with NHPs is compromised by poor access to evidence-based information and poor knowledge. Undergraduate pharmacy courses fall short of addressing real needs of practicing pharmacists to provide adequate NHP-related counseling and education. A perception of NHPs and CAM as safe still exists among pharmacists, and regulations related to NHPs require addressing to follow best practice and ensure patient safety. Continuing professional pharmacy-education programs should play a role in improving knowledge related to NHPs in addition to providing activities revolving around professional practice and health care ethics.

\section{Acknowledgments}

We thank Dr Sherief Khalifa for providing expert advice on knowledge questions, and Dr Ahmed Awaisu for providing statistical advice.

\section{Disclosure}

The authors report no conflicts of interest in this work.

\section{References}

1. Helgadóttir B, Vilhjálmsson R, Gunnarsdóttir TJ. [Utilization of complimentary and alternative health services in Iceland]. Laeknabladid. 2010;96:267-273. Icelandic.

2. Ramsay NA, Kenny MW, Davies G, Patel JP. Complimentary and alternative medicine use among patients starting warfarin. Br J Haematol. 2005;130:777-780.

3. Ashikaga T, Bosompra K, O’Brien P, Nelson L. Use of complimentary and alternative medicine by breast cancer patients: prevalence, patterns and communication with physicians. Support Care Cancer. 2002;10: $542-548$.

4. Olatunde S, Boon H, Hirschkorn K, Welsh S, Bajcar J. Roles and responsibilities of pharmacists with respect to natural health products: key informant interviews. Res Social Adm Pharm. 2010;6:63-69.

5. Byrne A, Boon H, Austin Z, Jurgens T, Raman-Wilms L. Core competencies in natural health products for Canadian pharmacy students. Am J Pharm Educ. 2010;74:45.

6. Farrell J, Ries NM, Boon H. Pharmacists and natural health products: a systematic analysis of professional responsibilities in Canada. Pharm Pract (Granada). 2008;6:33-42.

7. Cuzzolin L, Benoni G. Attitudes and knowledge toward natural products safety in the pharmacy setting: an Italian study. Phytother Res. 2009;23: 1018-1023.

8. Cook TF, Frighetto L, Marra CA, Jewesson PJ. Patterns of use and patients' attitudes toward complementary medications: a survey of adult general medicine patients at a major Canadian teaching hospital. Can J Clin Pharmacol. 2002;9:183-189.

9. Ernst E. Complementary medicine pharmacists? Pharm J. 2004;273: 197-198.

10. Kostka-Rokosz MD, Dvorkin-Camiel L, Asabigi AL. Student and faculty perspective toward the role and value of integration of natural product information into the pharmacy curriculum. J Diet Suppl. 2011;8: $12-18$.

11. Kreitzer MJ, Mitten D, Harris I, Shandeling J. Attitudes toward CAM among medical, nursing, and pharmacy faculty and students: a comparative analysis. Altern Ther Health Med. 2002;8:44-47, 50-53.

12. Lie DA, Boker J. Comparative survey of complementary and alternative medicine (CAM) attitudes, use, and information-seeking behaviour among medical students, residents and faculty. BMC Med Educ. 2006;6:58.

13. Pokladnikova J, Lie D. Comparison of attitudes, beliefs, and resourceseeking behavior for CAM among first- and third-year Czech pharmacy students. Am J Pharm Educ. 2008;72:24.

14. Sim SN, Levine MA. An evaluation of pharmacist and health food store retailer's knowledge regarding potential drug interactions associated with St John's wort. Can J Clin Pharmacol. 2010;17:e57-e63.

15. Charrois TL, Hill RL, Vu D, et al. Community identification of natural health product-drug interactions. Ann Pharmacother. 2007;41: 1124-1129.

16. Marshall MN. Sampling for qualitative research. Fam Pract. 1996;13: $522-525$. 
17. Neuman WL. Social Research Methods: Qualitative and Quantitative Approaches. 3rd ed. Boston: Allyn and Bacon; 1997.

18. Kwan D, Boon HS, Hirschkorn K, et al. Exploring consumer and pharmacist views on the professional role of the pharmacist with respect to natural health products: a study of focus groups. BMC Complement Altern Med. 2008;8:40.

19. Zeolla MM, Cerulli J. Use of and familiarity with dietary supplement information references by practicing pharmacists. J Am Pharm Assoc. 2008;48:401-404.

20. Riccard CP, Skelton M. Comparative analysis of 1st, 2nd, and 4th year MD students' attitudes toward complementary alternative medicine (CAM). BMC Res Notes. 2008;1:84.
21. Boon H, Hirschkorn K, Griener G, Cali M. The ethics of dietary supplements and natural health products in pharmacy practice: a systematic documentary analysis. Int $J$ Pharm Pract. 2009;17:31-38.

22. Saper RB, Phillips RS, Sehgal A, et al. Lead, mercury, and arsenic in US- and Indian-manufactured ayurvedic medicines sold via the Internet. JAMA. 2008;300:915-923.

23. Park JJ, Beckman-Harned S, Cho G, Kim D, Kim H. The current acceptance, accessibility and recognition of Chinese and ayurvedic medicine in the United States in the public, governmental, and industrial sectors. Chin J Integr Med. 2012;18:405-408.

\section{Publish your work in this journal}

Drug, Healthcare and Patient Safety is an international, peer-reviewed open-access journal exploring patient safety issues in the healthcare continuum from diagnostic and screening interventions through to treatment, drug therapy and surgery. The journal is characterized by the rapid reporting of reviews, original research, clinical, epidemiological and post-marketing surveillance studies, risk management, health literacy and educational programs across all areas of healthcare delivery. The manuscript management system is completely online and includes a very quick and fair peer-review system. Visit http://www.dovepress.com/ testimonials.php to read real quotes from published authors.

Submit your manuscript here: http://www.dovepress.com/drug-healthcare-and-patient-safety-journal 